\title{
Demanda de vivienda de interés social y efectividad de incentivos de la política de subsidio familiar en Bogotá del 2000 al 2012
}

Carol Alejandra Bolívar-Silva*, Pedro Elías Galindo-León ${ }^{\star *}$

\footnotetext{
Magíster en Ciencias Económicas. Docente investigadora, Corporación Universitaria Republicana, Bogotá, Colombia.

Correo electrónico:

kamopet@hotmail.com

** Doctor en Sociología Jurídica. Docente investigador, Corporación Universitaria Republicana, Bogotá, Colombia. Correo electrónico: pedrogalindobogota@gmail.com
}

Recibido: 26 de enero del 2015 Aprobado: 30 de abril del 2015

Cómo citar este artículo: Bolívar-Silva, C. A. y Galindo-León, P. E. (2015). Demanda de vivienda de interés social y efectividad de incentivos de la política de subsidio familiar en Bogotá del 2000 al 2012. Cooperativismo \& Desarrollo, 23(106), 45-65. doi: http://dx.doi. org/10.16925/co.v23i106.1123

\section{Resumen}

Introducción: la política de vivienda de interés social (vIs) se ha diseñado para contribuir al mejoramiento de la calidad de vida de las familias de escasos recursos mediante la entrega de un subsidio en dinero, de acuerdo con las diferentes condiciones socioeconómicas. Metodología: para la entrega de los subsidios en Bogotá se tienen en cuenta los siguientes indicadores: coeficiente de utilización del subsidio de vivienda, tasas de interés para financiar vivienda en valor real UVR, índice de aprobación de créditos hipotecarios, variación del índice de precios de la vivienda nueva y usada, demanda de vivienda no vis y tasa de desempleo. Esto con el objetivo de determinar cómo es el comportamiento de la demanda de vivienda de interés social y la efectividad de los incentivos de la política. Resultados: el presente artículo de investigación resume los resultados encontrados durante la comparación de la estructura conceptual, teórica y normativa de la política de vis, mediante un análisis cualitativo que aparentemente muestra la efectividad de dicha política y el cumplimiento de los requerimientos en búsqueda de favorecer a las familias de escasos recursos. Conclusiones: con base en el modelo econométrico, se evidencia que existe poca efectividad del subsidio de vivienda en el dinamismo de la demanda de vis.

Palabras clave: interés, política, social, subsidio, vivienda. 


\title{
Demand for Social Interest Housing and Effectiveness of Incentives for Family Subsidy Policy in Bogotá from 2000
} to 2012

\begin{abstract}
Introduction: The policy for Social Interest Housing (vis from its Spanish acronym) has been designed to contribute towards improvement of the quality of life of families of limited means through the provision of a cash subsidy, according to the different socioeconomic conditions. Methodology: In Bogotá, the following indicators are taken into account: coefficient of use of the housing subsidy, interest rates for financing housing in real value, UVR, mortgage credit approval indicator, variation in the index of prices of new and used housing, demand for non-vis housing and employment rate. The objective is to determine the behavior of the Demand for Social Interest Housing (DEMVIS) and the effectiveness of the incentives of the policy. Results: This research article summarizes the results found during comparison of the conceptual, theoretical and regulatory structure of the Social Interest Housing policy through a qualitative analysis that apparently shows the effectiveness of that policy and the fulfillment of the requirements with the aim of favoring families of limited means. Conclusions: Based on the econometric model, it can be seen that the housing subsidy has little effect on the dynamism of the demand for Social Interest Housing.
\end{abstract}

Keywords: interest, policy, social, subsidy, housing.

\section{Procura por moradia para pessoas de baixos recursos e efetividade de incentivos da política de subsídio familiar em Bogotá de 2000 a 2012}

\section{Resumo}

Introdução: a política de moradia para pessoas de baixos recursos foi desenhada para contribuir com o melhoramento da qualidade de vida das famílias de baixos recursos mediante a entrega de um subsídio em dinheiro, de acordo com as diferentes condições socioeconômicas. Metodologia: em Bogotá (Colômbia), consideram-se os seguintes indicadores: coeficiente de utilização do subsídio de habitação, taxas de juros para financiar a moradia em valor real UVR, índice de aprovação de créditos hipotecários, variação do índice de preços da habitação nova e usada, procura por moradia para pessoas de baixos recursos e taxa de desemprego. Isso com o objetivo de determinar como é o comportamento da procura por moradia para pessoas de baixos recursos e a efetividade dos incentivos da política. Resultados: este artigo de pesquisa resume os resultados encontrados durante a comparação da estrutura conceitual, teórica e normativa da política de moradia para pessoas de baixos recursos por meio de uma análise qualitativa que mostra aparentemente a efetividade dessa política e o cumprimento dos requisitos de busca por favorecer as famílias de baixos recursos. Conclusões: com base no modelo econométrico, evidencia-se que há pouca efetividade do subsídio de habitação no dinamismo da procura por moradia para pessoas de baixos recursos.

Palavras-chave: interesse, política, social, subsídio, habitação. 


\section{Introducción}

Al finalizar la década de los años ochenta, la administración del Estado planteó la necesidad de solucionar el problema de déficit habitacional existente en el país, mediante una reforma estructural dirigida a innovar las políticas e instrumentos de financiación de vivienda vigentes en esa época. Esta discusión derivó en la Ley $3^{\text {a }}$ de 1991, con la cual se reorientó la políti$\mathrm{ca}$, de acuerdo con las tendencias macroeconómicas, hacia un esquema de subsidios basado en los mecanismos del mercado. Bajo este esquema, el Estado abandonó su papel de intermediario financiero y constructor de vivienda y se sustituyó al Instituto de Crédito Territorial (ICT) por el Instituto Nacional de la Vivienda y la Reforma Urbana (Inurbe), institución que se encargaría de asignar los subsidios a cargo del presupuesto nacional, pero después este mecanismo estaría a cargo de las cajas de compensación familiar y el Fondo Nacional de Vivienda (Fonvivienda), con el fin de agilizar la entrega del subsidio familiar de vivienda (sFv) a la población vulnerable.

Aunque hay estudios relacionados con el déficit de vivienda, estos toman como fuente principal los periodos censales de 1993 y del 2005, y las encuestas de hogares que suministran información de los habitantes de la ciudad capital. Una forma de abordar el déficit de vivienda, que corresponde al faltante de unidades habitacionales frente a la cantidad de hogares existentes en la ciudad, es a través del estudio de la demanda de vivienda, especialmente de la vis que se destina a hogares de estrato socioeconómico bajo. Los beneficiarios deben cumplir ciertas condiciones estipuladas por ley, para recibir el SFV.

Dadas las condiciones de adquisición de la vis, se plantea la pregunta: ¿la política de subsidio ha sido efectiva para la adquisición de vivienda de interés social en Bogotá? y se formula como hipótesis que los subsidios a la VIS son relevantes a la demanda de vivienda en la ciudad y articulan soluciones de equidad en las variables sociodemográficas, la tasa de desempleo, las variaciones del precio y la demanda de vivienda.

Existen consideraciones metodológicas particulares a las dinámicas del subsidio de vivienda en Bogotá.

La problemática del déficit habitacional no es una cuestión de oferta y demanda de soluciones habitacionales únicamente, es necesario analizar el entorno en que se desarrolla esta dinámica en el país.
Se requiere realizar un estudio con metodología cualitativa que aborde aspectos socioeconómicos de los hogares postulantes a la vivienda, de las políticas nacionales en materia de vivienda social, de las entidades gubernamentales que las aplican y vigilan, de cómo se incorporan las políticas en los planes de desarrollo, cómo se asignan los recursos del presupuesto nacional y cuál es la cobertura de los servicios públicos.

Es decir, las limitaciones que se pueden detectar en la oferta formal de vivienda social en Colombia no son únicamente el resultado de factores que restringen el mercado. Por esta misma razón, se puede decir que la eficacia, no solo del subsidio, sino también de la política nacional de vivienda, debe medirse por el débil control institucional, por la informalidad de la vivienda, por los altos niveles de desempleo y los bajos ingresos de quienes demandan vivienda. El subsidio de vivienda es redistributivo del ingreso que se justifica cuando las familias no tienen acceso a los servicios financieros (Le Blanc, 2005).

En consecuencia, desde el punto de vista metodológico se utiliza un enfoque cualitativo para caracterizar a los hogares que requieren vivienda social en Bogotá, y se utiliza otro enfoque que utiliza herramienta econométrica para especificar un modelo que se aproxime a la eficiencia del SFv. No se pretende cuestionar las políticas ni diseñar estrategias que las entidades de orden local o nacional consideren dentro de su planeación, sino más bien descubrir factores que miden la eficiencia del subsidio familiar.

\section{Consideraciones teóricas y conceptuales sobre la demanda de vivienda y su relación con la eficiencia del subsidio}

En la década de los ochenta, el principal objetivo de los gobiernos fue combatir la pobreza y la exclusión social de una gran proporción de la población, y eso mismo fue ratificado por las Naciones Unidas en su Cumbre del Milenio. En los países en vías de desarrollo, estas iniciativas estaban asociadas con cambios estructurales que procuraran una reconversión en su aparato productivo y realizaran ajustes estructurales que fomentaran un crecimiento económico más equitativo y que reflejara una mejor redistribución del ingreso nacional por medio de mayor generación de empleo.

Los retos no solo estaban del lado de la aplicación de políticas económicas que generaran crecimiento 
económico, sino de políticas sociales que paralelamente trataran de solucionar problemas de calidad de vida de una creciente población urbana, que en Colombia fue motivada en alguna medida por las migraciones forzadas del campo a la ciudad como desplazamiento, ausencia del Estado en esas zonas deprimidas, entre otras.

Desde este momento, se abrieron espacios que implican la redefinición de políticas sectoriales relacionadas con salud, educación, vivienda, hábitat y medio ambiente. En Colombia se empezaron a diseñar políticas de vivienda que beneficiaron la provisión de unidades habitacionales nuevas. En una primera fase de la política se incorpora en los años setenta la política de vivienda dentro del sector de la construcción, como sector líder (Plan de Desarrollo "Las Cuatro Estrategias"; DNP, 1972), que generaría mayor crecimiento en la economía, porque utiliza un menor componente importado y utiliza mano de obra no calificada.

Esta estrategia implicaba la creación de un mecanismo para la financiación de la vivienda que no lesionara las inversiones del sector financiero como consecuencia de las altas tasas inflacionarias, se creó entonces la unidad de poder adquisitivo constante (UPAC), que se convirtió en un tropiezo para la adquisición de vivienda, porque terminó encareciéndola.

El sector financiero busca altas rentabilidades que se incrementan cuando se crean burbujas inmobiliarias que favorecen las construcciones lujosas de alto costo, como consecuencia del lavado de activos, la corrupción administrativa, demandas ficticias causadas por la especulación financiera.

En Colombia, el modelo de construcción de vivienda nueva, al igual que en los demás países latinoamericanos generó un crecimiento horizontal de las ciudades, agotando la disponibilidad de terrenos para construcción, lo cual no benefició para nada el mejoramiento de barrios y la renovación urbana, es decir, trabajar sobre la ciudad construida. La política de vivienda centrada en soluciones habitacionales nuevas causaría un deterioro en centros urbanos, degradación del paisaje urbanístico y pondría en riesgo el patrimonio histórico, por esa razón, se debe pensar en una política integral de hábitat. Lo anterior tiene implícito un concepto importante que es la "vivienda digna", aquella que cumple con calidad de la construcción, espacio físico apropiado y dotación de servicios públicos básicos como agua, alcantarillado y luz, entre otros. Además, porque organismos internacionales como las Naciones Unidas, en sus conferencias sobre hábitat, hacen recomendaciones sobre la calidad de vida, que los países en desarrollo incorporan en sus políticas internas para mitigar el problema social.

Finalmente, cabe decir que, en la última década, el énfasis se está focalizando en políticas de seguridad alimentaria para elevar la productividad y reducir los costos de atención en salud pública mediante el concepto de "ciudades saludables", lo cual implica implementar instrumentos de política que enlacen lo urbano y lo rural en encadenamientos productivos basados en liberar la demanda, actuando en la organización de los consumidores para la compra masiva de alimentos saludables, de modo que las organizaciones cooperativas de consumo son un canal de distribución adecuado.

\section{Aspectos conceptuales de la política social de vivienda}

Hablar de una política social de vivienda implica dilucidar la íntima relación que se da entre la práctica política del Estado y los procesos de acumulación de la riqueza en unas pocas personas de la masa poblacional, lo cual, junto con los procesos cíclicos de las políticas redistributivas, llevó a invalidar las propuestas que pretendían atender las necesidades de la sociedad. Esta dinámica, junto con las concepciones evolucionistas sobre progreso social que se gestaron en el siglo $\mathrm{xx}$, hicieron que los ciudadanos menos favorecidos emprendieran acciones de exigibilidad de sus derechos humanos, las cuales fueron tomando una tendencia hacia la escalabilidad y no se quedaron solamente en una aspiración moral, como pasaba con los derechos económicos, sociales y culturales. Esta situación posicionó a los ciudadanos como interlocutores y actores sociales capaces de visibilizar la situación de vulnerabilidad de sus derechos y requerir políticas que atendieran la necesidad de vivienda como algo fundamental e inalienable.

El enfoque en la necesidad de vivienda diluye la esencia del problema de la población pobre, que es la alimentación saludable y los altos costos que esta tiene para ellos, que compran al final de los canales de distribución de alimentos. Un reenfoque del problema en crear sistemas de economía que permitan acceder a una buena nutrición y al ahorro por medio de economías de escala que brindan las cooperativas de consumidores como punta final del encadenamiento productivo, facilita no solo el ahorro programado para la cuota inicial en la adquisición de vivienda, sino también el pago del compromiso hipotecario que surge con los bancos comerciales después de acceder a los subsidios de vivienda. Aquí entran en juego los restaurantes cooperativos desde donde se construye la cultura cooperativa y se vislumbran los proyectos de vivienda 
Harvey Suárez (2003), en su obra Desplazamiento forzado: dinámicas de guerra, exclusión y desarraigo, hace algunas reflexiones para comprender la formación del desplazamiento forzado como un campo de saber, poder y subjetividad. El autor anota que:

Toda política pública debe partir de la percepción de las personas afectadas y debe garantizar condiciones políticas y económicas para el cumplimiento del derecho vulnerable, a diferencia de la dinámica que se venía presentando que no favorecía el nexo existente entre políticas sociales y acumulación.

En este orden de ideas se entiende la efectividad de una política o un programa cuando se logran los objetivos que le dieron su razón de ser.

Un objetivo bien definido explicita lo que se busca generar, incluyendo la calidad de lo que se propone; asimismo, un objetivo debe delimitar el tiempo en que se espera generar un determinado efecto o producto: "La efectividad es el grado en que se cumplen los objetivos de una iniciativa al menor costo posible, el no cumplir cabalmente los objetivos o el desperdicio de recursos e insumos, hacen que la iniciativa sea menos efectiva o completamente ineficiente" (Mokate, 2001, p. 3).

Esta postura de Mokate permite inferir que la efectividad implica cumplir los objetivos esperados, en el tiempo previsto y optimizando los recursos e insumos requeridos. Por otra parte, "la ley debe tratar de compensar las barreras económicas y sociales que dificultan la realización del potencial individual. Pese a que no se confunde con la igualdad, la equidad siempre está relacionada con la superación de las desigualdades" (Mokate, 2001).

En consonancia, y dada la imposibilidad del Estado de atender los requerimientos de sus ciudadanos, al momento de medir las políticas públicas según los criterios de efectividad se acude con argucias a reformas económicas de mercado, en las cuales los sectores que ofertan la satisfacción de las demandas públicas son sustituidos por los privados y aquellos se convierten en reguladores y promotores. Así las cosas, lo que forma parte de la política pública de vivienda ya no es la construcción por parte del Estado de la vivienda, sino la oferta de "subsidiarios" de vivienda a familias y personas en situación de extrema pobreza, con lo cual se ven las condiciones de hábitat en el contexto más amplio de bienes públicos como áreas recreativas, de deportes y salones comunales. La tarea ahora no es garantizar el techo sino ser garante de que los oferentes que reciben los subsidios del Estado cumplan con las normas fijadas por este en materia de "vivienda digna" sin perjuicio de observar los estándares y precios de las viviendas de interés social nuevas, la asignación de subsidios, los requisitos de ahorro previo, el acopio de suelo para vis y las condiciones de entrada de empresas privadas a la construcción de estas viviendas.

Así, y según lo plantea el Informe final definitivo de UN-HABITAT y Naciones Unidas (2007), titulado Evaluación del ahorro programado en el acceso al crédito para vivienda de interés social, hoy por hoy forman parte de la política pública de vivienda los siguientes factores:

a) Subsidios a la demanda de vivienda: consistentes en una erogación de dinero por parte del Estado para operar la capacidad de compra del inmueble. En este orden, hacen posible que sus beneficiarios cuenten con una cantidad de dinero que constituye garantía real para elegir la vivienda. El subsidio de vivienda es transversalizado por la neutralidad, la cual consiste en que los beneficiarios puedan elegir entre distintas opciones para lograr viviendas con un determinado estándar.

b) Ahorro previo: se trata de un aporte propio al financiamiento de sus viviendas que hace la persona a la que le será adjudicado el subsidio de vivienda. La cantidad de dinero ahorrado dependerá de la vivienda y del nivel de sus ingresos. El objetivo de este ahorro programado es disminuir el pago de intereses por concepto de crédito hipotecario.

Es importante resaltar que la "construcción social del espacio", como la concibe, entre otros, el profesor de la Universidad del Valle, Otto Valderrutén, lleva a considerar a las empresas constructoras de vivienda en dos categorías: las financieras, que forman parte de las holding de los grupos financieros, y las de servicios profesionales, conformadas generalmente por arquitectos y constructores. En ambas prima el criterio de eficiencia económica, basada en reducción de costos, vía calidad y pocos amoblamientos urbanos, los cuales quedan a cargo del Estado, que usualmente no los incluye en el presupuesto de inversión.

El profesor Valderrutén también anota que las cooperativas de vivienda aplican una serie de tecnologías sociales que parten del autofinanciamiento, la 
utilización de mano de obra propia para reemplazar procesos maquinados, utilización de materiales alternativos propios de la región para ahorro energético y transporte, lo mismo que la reducción de los costos futuros de sostenimiento mediante diseños alternativos para el manejo de aguas servidas, desechos y residuos sólidos adicionales a la explotación sostenible de recursos locales, para implantar proyectos productivos generadores de empleo. A partir de una reflexión respecto a esta teoría, en un trabajo de un grupo transdisciplinar de Hábitat-Coop y 15 arquitectos de Universidad del Valle, adelantado durante seis meses en la pasada década, surgió la propuesta de "Construcción cooperativa del hábitat", y después el modelo de la Esmeraldacoop (Estrada Calderón, 2015; www.habitat-coop.com) .

\section{Contexto de la política de vivienda de interés social}

Desde los años treinta, en Colombia, se han venido articulando políticas gubernamentales en materia de vivienda, las cuales responden a las necesidades de la población, especialmente en el área urbana porque los crecientes flujos migratorios creaban un déficit habitacional cada vez más importante y una informalización de la vivienda en área subnormal. Para tal fin, el Gobierno creó dos mecanismos: el Instituto de Crédito Territorial y el Banco Central Hipotecario, que tenían la responsabilidad de ofertar y financiar la vivienda dirigida a personas de escasos recursos económicos. Por décadas, la ejecución de la política de vivienda estuvo a cargo de estas dos entidades; sin embargo, en la década de los setenta hubo un viraje hacia la financiación del sector constructor, razón por la cual se creó, por una parte, la herramienta UPAC, reemplazado por la unidad de valor real (UVR), y por otra parte el subsidio familiar, que a partir de la Constitución del 91 vino a apoyar la política social de "vivienda digna" y la visión económica. "El Estado promoverá planes de Vivienda de Interés Social, sistemas adecuados de financiación a largo plazo y formas asociativas de ejecución de estos programas de vivienda" (art. 51 de la Constitución Política de Colombia). A partir de ese momento, muchos cambios se han presentado en la normatividad relacionada con la política de vivienda, se han liquidado entidades, se han creado otras, se han redefinido conceptos. A continuación se presenta un resumen de la normatividad más representativa.

\section{La política de vivienda en Bogotá entre 1998-2011}

En todos los planes de desarrollo se reconoce la informalidad de la construcción en muchas localidades del Distrito Capital, el asentamiento humano en zonas de riesgo y el déficit habitacional. Es incuestionable que cada administración descubre en la problemática de la vivienda unos factores diversos y unas soluciones tambien diversas. Este hecho, en líneas generales, se observa en la tabla 1 , en la que se hace una comparación de las políticas de vivienda en el periodo 1998-2011, que muestra la propuesta de Enrique Peñalosa: una promoción de la vis desde la perspectiva del control de precios a la tierra urbanizable con un concepto de dotación de servicios y vías de comunicación, creación de banco de tierras, reubicación de familias en zonas de alto riesgo. Para Antanas Mockus, en el periodo 2001-2004, la urbanización ilegal debe ser controlada y facilitar la oferta inmobiliaria renovando suelos. Sin embargo, considera que se debe renovar la ciudad construida conservando el patrimonio arquitectónico. Luis Eduardo Garzón propone en su Plan de Desarrollo una renovación urbana y una mejora de barrios dotándolos de servicios públicos, es decir, presta atención al déficit cualitativo de vivienda y considera que se proveerá de vivienda de interés prioritario a las familias de escasos recursos económicos. Finalmemte, Samuel Moreno entre 2008-2011, incorpora en su Plan de Desarrollo proyectos ambiciosos que ofrecen alrededor de 75000 vis, soluciones de vivienda a 4000 familias desplazadas y titulación de predios a viviendas de estratos 1 y 2 .

\section{La vivienda de interés social y el subsidio familiar de vivienda}

Con la Constitución Política de Colombia de 1991, el concepto de la vis pasa a adscribirse dentro del marco de los derechos humanos generando un nuevo término: vivienda digna, ello en respuesta a los ingentes debates por parte de organizaciones de la sociedad civil, a los cuales se han unido grupos fuertes de la comunidad internacional, los cuales consideran que las condiciones de hábitat que se venían dando en Colombia no garantizaban un nivel de bienestar mínimo a un ser humano, situación que conllevó la creación de un nuevo cuerpo normativo que respondiera a los pactos del derecho internacional público a los cuales se ha acogido el país (Naciones Unidas. Pacto 
Tabla 1

Comparación de las políticas de vivienda

\begin{tabular}{lllll}
\hline Tipo de política & \multicolumn{1}{c}{$\begin{array}{c}\text { Enrique Peñalosa } \\
\text { 1998-2001 }\end{array}$} & \multicolumn{1}{c}{$\begin{array}{c}\text { Antana Mockus } \\
\text { 2001-2004 }\end{array}$} & $\begin{array}{c}\text { Luis Eduardo Garzón } \\
\text { 2004-2008 }\end{array}$ & \multicolumn{1}{c}{$\begin{array}{c}\text { Samuel Moreno } \\
\text { 2008-2011 }\end{array}$} \\
\hline $\begin{array}{l}\text { Asentamientos } \\
\text { humanos }\end{array}$ & $\begin{array}{l}\text { Reubicación de familias } \\
\text { en zonas de alto riesgo }\end{array}$ & $\begin{array}{l}\text { Reasentamiento de } \\
\text { familias }\end{array}$ & $\begin{array}{l}\text { Promoción de acciones } \\
\text { para prevenir y controlar } \\
\text { riesgos }\end{array}$ & $\begin{array}{l}\text { Reasentamiento de familias en } \\
\text { zonas de alto riesgo no mitiga- } \\
\text { ble. Proyecto: "Mi casa territorio } \\
\text { seguro". Ofrecer solución de } \\
\text { vivienda a familias desplazadas, } \\
\text { alrededor de 3000 familias. Pro- } \\
\text { yecto: "Bogotá me acoge" }\end{array}$ \\
\hline $\begin{array}{l}\text { Programas } \\
\text { de vis }\end{array}$ & $\begin{array}{l}\text { Promoción de la vis, } \\
\text { controlando precios } \\
\text { de la tierra }\end{array}$ & & $\begin{array}{l}\text { Ofrecer 74 920 soluciones de } \\
\text { vivienda nueva (vis) }\end{array}$ \\
\hline $\begin{array}{l}\text { Suelos urbaniza- } \\
\text { bles para vis }\end{array}$ & $\begin{array}{l}\text { Banco de tieras } \\
\text { Metrovivienda }\end{array}$ & $\begin{array}{l}\text { Generar y renovar } \\
\text { suelos para facilitar } \\
\text { la oferta inmobiliaria }\end{array}$ & $\begin{array}{l}\text { Desarrollo de suelo } \\
\text { urbano y mejoramiento } \\
\text { de barrios }\end{array}$ & $\begin{array}{l}\text { Titulación de predios, reconoci- } \\
\text { miento de viviendas estrato 1 y 2 }\end{array}$ \\
\hline $\begin{array}{l}\text { Barrio, localidad, } \\
\text { equipamentos } \\
\text { metropolitanos }\end{array}$ & $\begin{array}{l}\text { Desmarginalización de } \\
\text { barrios y mejoramiento } \\
\text { de infraestructura vial }\end{array}$ & $\begin{array}{l}\text { Control de la } \\
\text { urbanización ilegal }\end{array}$ & $\begin{array}{l}\text { Renovación urbana con } \\
\text { mejoras en condiciones de } \\
\text { servicios públicos }\end{array}$ & $\begin{array}{l}\text { Mejorar condiciones de habitabi- } \\
\text { lidad, soluciones de vivienda en } \\
\text { sitio propio }\end{array}$ \\
\hline
\end{tabular}

Nota. Tomada de Planes de Desarrollo. Alcaldía Mayor de Bogotá

Internacional de Derechos Económicos, Sociales y Culturales [ICESCR], 16 de diciembre de 1966), a la Declaración de Vancouver sobre Asentamientos Humanos (Naciones Unidas, del 31 de mayo al 11 de junio de 1976) y a la Segunda Conferencia de las Naciones Unidas sobre el Hábitat (Naciones Unidas, del 3 al 14 de junio de 1996).

El concepto de vivienda digna se encuentra estrechamente relacionado con la política de subsidio a través de demanda, dado que su costo es cubierto en parte por el ciudadano y abarca además el conjunto de atributos que debe tener la vivienda, como son la titulación, la disponibilidad de servicios, la ubicación y la habitabilidad, entre otros. Sin embargo, en esta interpretación también se involucran otros aspectos, como la necesidad de cubrir a poblaciones que son víctimas del desplazamiento forzado, a familias enteras sin hogar, a habitantes de la calle en procesos de rehabilitación, es decir, se trata de crear las condiciones para que a partir de un lugar adecuado de vivienda se puedan adelantar procesos de inclusión social en estas grandes franjas de la población, lo cual no es ajeno a lo ya consagrado en el artículo 51 de la Constitución Política de Colombia (véase anexo 01).

Del anterior artículo no solo se puede afirmar la concordancia con el siguiente cuerpo normativo: la ley 82 de 1993 [artículos del 12 al 14] y la ley 418 de
1997 [artículos 29 al 34], sino que deja por sentado que la vivienda es un derecho y que para su goce efectivo debe tener un carácter digno. Esta connotación que hemos visto en el artículo 51 de la Constitución Política de Colombia tiene un carácter imperativo y de obligación directa del Estado; por tanto, debe ser él mismo, a través de las entidades que conforman el cuerpo administrativo o por las entidades asociativas que sean creadas para tal fin, quienes lo lleven a cabo. A este respecto, se entiende que su carácter es asistencial, por lo que la Corte Constitucional al ser consultada dijo que aunque no es un derecho inalienable, el Estado sí debe proporcionar las medidas necesarias para garantizar a los colombianos una vivienda con condiciones de igualdad y unos parámetros legales específicos. De lo anterior entendemos por qué las acciones estatales solo podrían llegar hasta el desarrollo de planes de VIS, sistemas financieros de amplia cobertura y la promoción de formas asociativas para el desarrollo de dichos programas.

La vivienda pasa de ser un bien de primera necesidad a un derecho inalienable y va en relación con el desarrollo territorial, social y económico del país, con lo cual se estarían superando condiciones de desigualdad, se generaría empleo y se promoverían diversas formas de crecimiento económico, en la medida en que para su realización se involucra a un amplio 
número de sectores ${ }^{2}$. Lo anterior es ampliado en el artículo 91 de la ley 388 de 1997 (véase anexo 3), que entiende por vis todas aquellas acciones que se desarrollen para garantizar el derecho a la vivienda de los hogares de menores ingresos. El Gobierno Nacional es el que define el tipo y precio máximo de las soluciones destinadas a estos hogares, teniendo en cuenta aspectos como las características del déficit habitacional $^{3}$, las posibilidades de acceso al crédito de los hogares, las condiciones de la oferta, el monto de recursos de crédito disponibles por parte del sector financiero y la suma de fondos del Estado destinados a los programas de vivienda.

En consonancia con lo establecido en la Constitución Política, los acuerdos internacionales y el fallo de la Corte sobre la vivienda digna, la administración del Estado, en atención a la demanda de vis, crea el SFV, que es un aporte en dinero o en especie proveniente del erario público que se otorga por una sola vez al beneficiario, sin cargo de restitución por parte de este, que constituye un complemento de su ahorro, para facilitarle la adquisición, construcción o mejoramiento de una solución de vis ${ }^{4}$ (ley $3^{\text {a }}$ de 1991, art. $6^{\circ}$ y decreto $2620 / 2000$, art. $2^{\circ}$ ). En otras palabras, es un subsidio que da el gobierno para todas aquellas personas que no tengan vivienda, necesitan mejorarla, o tienen lote y necesitan construir en sitio propio.

De acuerdo con el decreto 2620 del 2000, modificado por los decretos 2480 y 2488 del 2002, las entidades otorgantes del SFV son las cajas de compensación familiar y la entidad ejecutora de este rubro cuando se trate de recursos del presupuesto nacional. Sin embargo, la asignación de subsidios de vivienda con recursos destinados para tal fin por el Gobierno Nacional puede ser desarrollada por las cajas de compensación familiar, reunidas en unión temporal, previa celebración

\footnotetext{
2 Según la tesis de Currie (1993), incentivar el sector de la construcción implica un mayor empleo de mano de obra y una mayor utilización de la capacidad instalada, lo que posteriormente va tener efecto sobre los sectores de la industria y la agricultura, ya que el mayor ingreso percibido por la población provocaría un incremento en el consumo de los bienes y servicios, lo que conduciría finalmente al aumento de la producción agregada del país.

3 En los estudios de la Cepal y de las Naciones Unidas se identifican dos tipos de déficit: cuantitativo y cualitativo. El primero de ellos se basa en la comparación del número de hogares y de viviendas permanentes, y el segundo se refiere a aquellas viviendas que presentan una calidad insatisfactoria en relación con la disponibilidad de los servicios públicos, el estado de la construcción de la vivienda y el hacinamiento.

$4 \quad$ El aporte estatal en especie puede estar representado en lotes de terreno de propiedad de entidades públicas nacionales.
}

de un contrato con la entidad ejecutora del rubro. Tales asignaciones se deben dirigir prioritariamente a atender las postulaciones de la población más pobre, dentro de la cual se encuentran las personas no vinculadas al sistema formal de trabajo. Con los recursos destinados por las cajas de compensación familiar, se debe atender en forma prioritaria a las personas afiliadas al sistema formal de trabajo (D. 2620/2000, art. 8; D. 2480/2002, art. $1^{\circ}$.

El decreto 2620 del 2000, que reglamenta parcialmente la ley $3^{\mathrm{a}}$ de 1991 en relación con el SFV en dinero y en especie para áreas urbanas, la ley 49 de 1990, en cuanto a su asignación por parte de las cajas de compensación familiar, y la ley 546 de 1999, en relación con la vis, del cual también debe dejarse sentado que fue parcialmente derogada con el decreto 975 del 2004, también postula que las personas que pueden ser beneficiadas por SFV son aquellas que conforman hogares no vinculados al sistema formal de trabajo o aquellas afiliadas a las cajas de compensación familiar que carezcan de recursos suficientes para obtener o mejorar una única solución de vis ${ }^{5}$, cuyos ingresos totales mensuales no sean superiores al equivalente a cuatro salarios mínimos mensuales legales vigentes. Adicionalmente, para aspirar a la asignación de un SFV, los solicitantes deben cumplir con las siguientes condiciones:

a) No haber sido beneficiario del subsidio.

b) Conformar un núcleo familiar que compartan el mismo espacio habitacional ${ }^{6}$.

c) No ser propietario de vivienda excepto para mejoramiento.

d) Estar sujeto a la evaluación de su capacidad de crédito para la adquisición, construcción o mejoramiento de la solución de vivienda, salvo que dicho crédito no se requiera.

e) Tener un ahorro previo mínimo del $10 \%$ del valor de la vivienda que se desea adquirir ${ }^{7}$ (Ministerio de Desarrollo Económico, 2000).

\footnotetext{
5 Se entiende por hogar el conformado por los cónyuges e hijos, las uniones maritales de hecho y/o el grupo de personas unidas por vínculos de parentesco hasta tercer grado de consanguinidad, segundo de afinidad y primero civil, que compartan un mismo espacio habitacional (decreto 2620 del 2000, arts. 5 y 6, y decreto 2480 del 2002, art. 4).

6 Este núcleo familiar puede estar conformado por hijos, cónyuges, uniones maritales de hecho, parentesco hasta de tercer grado de consanguinidad, segundo grado de afinidad y primero civil.

$7 \quad$ La posesión de un terreno reemplaza al ahorro previo en el caso de construcción sobre dicho sitio.
} 
Para realizar el ahorro previo existen las siguientes modalidades: el ahorro programado, los aportes periódicos realizados en fondos comunes especiales y en los fondos mutuos de inversión, las cesantías depositadas en fondos públicos o privados de cesantías y en el Fondo Nacional del Ahorro. Cabe decir que el ahorro programado es el que se realiza mediante la constitución de depósitos de ahorro en "Cuentas de Ahorro para la Vivienda” en: establecimientos de crédito vigilados por la Superintendencia Financiera, las cooperativas de ahorro y crédito y multiactivas e integrales con sección de ahorro y crédito, previamente autorizadas por la Superintendencia de la Economía Solidaria, los fondos de empleados vigilados por la Superintendencia de la Economía Solidaria y el Fondo Nacional de Ahorro (Ministerio de Desarrollo Económico, art. 35, modificado por el art. $9^{\circ}$ del decreto 2488/99).

Finalmente, es importante mencionar que el valor del subsidio depende del tipo de vivienda que se desee adquirir y del número de habitantes que tenga el municipio donde está ubicada, de tal manera que puede oscilar entre 10 y 22 salarios mínimos mensuales legales cuando se trate de compra de vivienda, y entre 8 y 11,5 salarios mínimos mensuales legales cuando se trate de mejoramiento de vivienda. No obstante, en la fecha de su asignación, la cuantía del subsidio no puede ser superior al $60 \%$ del valor o precio de la vivienda que se desee adquirir o construir, o al 90\% de la mejora que se vaya a realizar (Ministerio de Desarrollo Económico, 2000, art. 12, modificado por el art. $1^{\circ}$ del decreto $2342 / 2001$ y el art. $3^{\circ}$ del decreto 2488/2002).

\section{Aspectos institucionales de la actual política de vis centrada en el subsidio}

La experiencia institucional colombiana en materia de vis data de 1939, cuando se creó el Instituto de Crédito Territorial (ICT), entidad encargada de construir y otorgar créditos para la compra de vivienda en los grupos menos favorecidos a través de subsidios, créditos con bajas tasas de interés y el precio mínimo de las viviendas, las cuales construía directamente o por contrato con urbanizadores privados (Chiappe de Villa, 1999). Con la ley $3^{\text {a }}$ de 1991, se reorienta la política del ICT, de acuerdo con las tendencias internacionales, hacia un esquema de subsidios basado en mecanismos de mercado. De esta forma, el Estado abandonó su papel de intermediario financiero y constructor de vivienda y se sustituyó el ICT por el
Instituto Nacional de Vivienda de Interés Social y Reforma Urbana (Inurbe), entidad encargada de administrar el sistema de subsidios con el objeto de fomentar soluciones de vivienda, prestar asistencia técnica y financiar a las administraciones locales, seccionales y a las organizaciones populares de vivienda (OPV), además de administrar los recursos nacionales del SFV y en las zonas rurales las oficinas de la Caja de Crédito Agrario, Industrial y Minero. Igualmente, el Inurbe estructuró normas de vivienda basadas en el esquema del subsidio a la demanda, que facilitarían a los hogares de menores ingresos la conformación de la cuota inicial requerida para la compra, la construcción o el mejoramiento de vivienda (Chiappe de Villa, 1999).

Debido a algunos brotes de corrupción y politiquería, el Gobierno liquidó al Inurbe y la mayoría de sus funciones fueron trasladadas a las cajas de compensación familiar, siendo reemplazado en las restantes por el Fonvivienda; adicionalmente, se determinó que parte de los fondos que manejan las cajas de compensación familiar ${ }^{8}$, que eran dineros correspondientes al subsidio familiar, entrarían en el programa y se destinarían a subsidios de vivienda. La operación de otros promotores oficiales más pequeños, como la Caja Promotora de Vivienda Militar', que desde 1994 otorga directamente subsidios con recursos propios, y lo que hoy es el Banco Agrario, también se reconvirtieron a este esquema.

En virtud de que esta investigación se centrará en evaluar la efectividad de las políticas de subsidio familiar de vivienda de interés social en Bogotá en el periodo comprendido entre el 2000 y el 2012, merecen una mención especial las opv y Fonvivienda, este último con mayor incidencia en dicho lapso. Como ya se enunció, después de la Constitución Política de 1991 se extrapola el denominado subsidio a los programas de vivienda y se crean, a través de la ley 9 de 1991, las OPV como entidades sin ánimo de lucro, que tendrán como misión el desarrollo de programas de vivienda para sus afiliados por sistemas de autogestión o participación comunitaria y las cooperativas

\footnotetext{
8 Son entidades de naturaleza privada que manejan recursos parafiscales deducidos de la nómina de los empleados, con el fin de alimentar un fondo de subsidios dirigido a trabajadores con ingresos inferiores a cuatro salarios mínimos mensuales legales vigentes.

9 El capital de esta caja está formado principalmente por un ahorro obligatorio que aportan periódicamente los miembros de las Fuerzas Armadas y los empleados civiles de esta.
} 
de ahorro y crédito que también contribuyen a la financiación de vis.

Tanto las OPV como las cooperativas de ahorro y crédito han tenido un vertiginoso desarrollo en las últimas décadas, lo cual se le atribuye a su sistema de autogestión o participación comunitaria, por lo que han sido el foco de atención por su importante papel en la promoción y construcción de vivienda para las clases menos favorecidas, aunque no manejan los recursos de los subsidios familiares de vivienda de interés social.

\section{Del UPAC y el UVR: la estructura financiera de la vivienda de interés social en Colombia}

No se puede pasar por alto el papel que han jugado en la política de vivienda de interés social los sistemas UPAC Y UVR. El primero de ellos, es decir, el sistema UPAC, fue establecido en el país a finales de 1972 en el gobierno de Misael Pastrana Borrero ${ }^{10}$ y su principal característica fue la utilización de un esquema de indexación que operó durante casi un cuarto de siglo con un alto grado de estabilidad. Lo anterior contrasta con la suerte que corrieron esquemas análogos que se aplicaron en otros países latinoamericanos, los cuales sucumbieron en coyunturas de agudización de la inflación o de crisis bancarias generales: el sistema colombiano sobrevivió a circunstancias similares y fue el eje de una actividad sostenida del sector durante este tiempo tan prolongado (CID, 2006).

El propósito inicial de la introducción de un mecanismo de indexación como el propuesto por el sistema UPAC era el de corregir los graves desajustes que le había implicado el aumento del nivel general de precios al esquema financiero anterior. Quizás el desajuste más notorio se relacionaba con los préstamos de largo plazo, los cuales, pactados a tasas fijas y con expectativas de inflación mucho más bajas, terminaron poco después en cuotas de amortización estrambóticas para los deudores. Por lo tanto, el mecanismo de indexación tenía dos objetivos, el primero de ellos mantener el valor real de los saldos de los préstamos pactados a largo plazo, y el segundo, de igual importancia que el anterior, garantizarles a los ahorradores una remuneración real positiva que no estuviera

10 Cabe resaltar que este Gobierno estuvo altamente influenciado por los planteamientos de Lauchlin Currie, quien fuese el autor del plan de desarrollo conocido con el nombre de "Las cuatro estrategias". sujeta a las variaciones en el nivel general de precios. La remuneración a los depósitos constaba entonces de una porción llamada corrección monetaria, que se ajustaba de manera continua con la inflación, y un pequeño interés adicional, mientras que a los usuarios del crédito se les cobraba la misma corrección monetaria y una tasa remunerativa.

Sin embargo, algunos gobiernos posteriores al de Pastrana que tenían reservas sobre la bondad del sistema, en distintos momentos, aplicaron una indexación que fue menor al ritmo del nivel general de precios. No obstante, esta situación no llevó a un colapso en los depósitos, por el contrario, se mantuvo un buen volumen de estos con cierto grado de estabilidad. La operación se concentraba en el hecho de que la combinación de liquidez y remuneración era suficiente para que un número significativo de ahorradores mantuviera sus depósitos en el sistema, a pesar de que sus beneficios reales eran bajos, e incluso negativos, pero era preferible a otras opciones que con una liquidez comparable tenían remuneraciones nominales nulas. De esta manera, el sector de la construcción pudo beneficiarse de unos fondos relativamente baratos, con una cierta autonomía de las fluctuaciones de la tasa de interés general, lo cual se apoyaba en un subsidio virtual por parte del ahorrador.

Claro está que el sistema UPAC también tuvo inconvenientes, pues en ciertas ocasiones se presentó un encarecimiento de los precios de la vivienda por efecto de racionamientos eventuales del crédito, ante aumentos coyunturales de la demanda por vivienda. Adicionalmente, la falta de orientación de los préstamos llevó a un notable aumento en la construcción de viviendas de lujo que, junto con la difusión de prácticas semilegales que les permitían a los intermediarios financieros cobrar intereses elevados, sobre todo a los constructores, condujo a que el sistema perdiera su credibilidad.

La grave situación económica del país que se reflejaba en los altos niveles de desempleo, en el deterioro de los ingresos de amplios sectores de la población y en el súbito encarecimiento del crédito, llevaron a que muchos deudores se vieran en la imposibilidad de pagar sus acreencias y, por ende, a una oleada de daciones en pago. Todo ello condujo a una caída en los precios de los inmuebles que ya estaban deprimidos y realimentó la espiral recesiva. Esta situación se hizo insostenible, y para evitar un colapso mayor el Gobierno realizó una vasta operación de salvamento que implicó, entre otras cosas, el abandono del sisteMa UPAC. 
Según el informe del Centro de Investigaciones para el Desarrollo (CID) de la Universidad Nacional y de la Contraloría General de la Nación (2006), la mala experiencia de un buen número de deudores que perdieron su patrimonio ha generado un gran temor entre los eventuales compradores que los conduce a posponer sus compras hasta tener un ahorro suficiente. Por su parte, los oferentes de vivienda también se sienten temerosos a endeudarse sin haber asegurado la venta de sus proyectos, y cada vez más utilizan esquemas de ventas sobre planos, que exigen pagos anticipados a los compradores y que implican comenzar la construcción solo cuando se ha vendido la mayor parte de los inmuebles.

Así como los compradores sienten temor por endeudarse, los bancos hipotecarios también son mucho más cautelosos a la hora de otorgar sus créditos, particularmente en el sector de vis. Los montos prestados globales han ido descendiendo, ya que los préstamos redimidos no compensan los nuevos créditos; incluso la cartera vencida y las daciones en pago han continuado y solo hasta hace poco empiezan a ceder. Esta situación demuestra que el nuevo sistema sigue generando insolvencia en un número importante de deudores. Por esa razón es necesario revisar en detalle las generalidades de la política de vivienda y observar localmente su tendencia en Bogotá, que es la mayor receptora de migración urbana en el país y en donde más se agudiza el problema del déficit habitacional.

\section{La política de vivienda de interés social y su relación con los subsidios en Bogotá}

La política de vis en Colombia está regulada por la ley 3 de 1991, con la cual se crea el Sistema Nacional de vivienda de interés social y se diseña el esquema del subsidio familiar para dinamizar la demanda de vivienda. El subsidio es un aporte del Estado en dinero o en especie no restituible siempre y cuando la persona beneficiaria haga uso de la vivienda por diez años y no haya cometido ningún fraude para la adjudicación del subsidio. Los recursos para el subsidio familiar tienen diferentes usos dependiendo de las características socioeconómicas y de vulnerabilidad del solicitante, porque se busca que el subsidio facilite la adquisición de vivienda nueva o usada, la construcción en sitio propio o la mejora de la vivienda existente, previo cumplimiento de los requisitos de ley, ya que el subsidio se otorga por una sola vez.

La política de vivienda es más eficiente en la medida en que se focalicen o detecten las familias más vulnerables y se pueda controlar el uso del subsidio, es decir, que haya una garantía de su correcto uso y no se le cambie su destinación.

Según la ley, el subsidio familiar aplica a postulantes con ingresos totales que no superen cuatro salarios mínimos mensuales legales vigentes, que demuestren además que no tienen recursos para adquirir una solución de vis y que conformen un grupo familiar de dos personas que comparten un mismo espacio habitacional.

El SFV es asignado por entidades que tienen bien definida su población objetivo: si los postulantes son empleados afiliados a una caja de compensación familiar, será esta quien establezca entre sus afiliados los hogares sujetos del beneficio. Si los postulantes son independientes o no están afiliados a una caja de compensación familiar, será Fonvivienda el que asigne el subsidio. Los primeros se consideran otorgantes formales y los segundos otorgantes informales.

Los montos del SFV varían entre un mínimo de \$2 060000 y un máximo de \$13 390000 dependiendo del puntaje asignado por el Sisbén al jefe de hogar.

Para garantizar el buen manejo de los recursos del SFV disponibles, la política de vivienda se articula con los entes territoriales para garantizar la oportuna ejecución de proyectos específicos habitacionales destinados a un segmento diverso de la población con características socioeconómicas bien definidas que requieren atención en su demanda de vivienda. Por lo tanto, los recursos del SFV se manejan por medio de once bolsas de destinación: concurso de esfuerzo territorial, bolsa única nacional, bolsa única de mejoramiento, bolsa ordinaria (en ella, el Gobierno entrega directamente los subsidios a los hogares de trabajadores independientes), población desplazada (no se les exige la condición del ahorro previo), desastre o calamidad pública, atentados terroristas, vivienda saludable, titulación, bolsa especial para concejales y bolsa especial para recicladores.

Un segmento importante de la población vulnerable no cumple con la condición del cierre financiero, es decir, el ahorro previo exigido a los hogares beneficiarios del subsidio de vivienda, por esa razón, alrededor del 50\% de los subsidios asignados entre 2006-2009 se distribuyeron entre la población 
desplazada y los hogares afectados por desastres naturales ${ }^{11}$.

\section{Ocupación del suelo en Bogotá: formal e informal}

La política general de vivienda cuenta con una limitante importante: el origen ilegal de la ocupación del suelo en la ciudad capital. En la figura 1, se muestran las áreas de mejoramiento en Bogotá para el periodo 1998-2001; allí se observa que el 65\% de las hectáreas urbanizadas provienen de la ilegalidad y el $23 \%$ de ciudad informal. Muchas veces, la incapacidad de las entidades regulatorias y de control urbano para contrarrestar el fenómeno de la urbanización ilegal hace que los urbanizadores piratas incrementen la oferta de vivienda. El crecimiento urbano informal también se facilita por el bajo nivel de ingresos que se registra en los hogares que demandan vivienda social y que no cumplen con la condición del cierre financiero para acceder al subsidio de vivienda, por lo tanto adquieren su vivienda a precios más bajos en zonas marginadas o precarias.

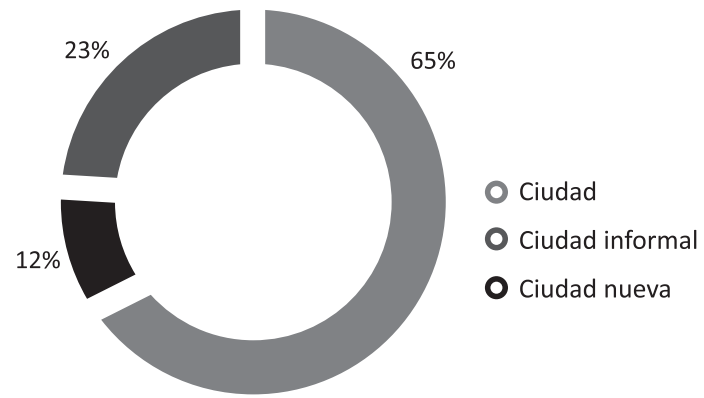

Figura 1. Áreas de mejoramiento en Bogotá. Tomado de Secretaría Distrital del Hábitat, Subsecretaría de Inspección, Vigilancia y Control de Vivienda.

En el mapa de Bogotá, Distrito Capital suministrado por la Secretaría Distrital del Hábitat se observa que la mayor parte del suelo urbanizado tiene origen informal. Según la misma fuente, alrededor del 23\% es área urbanizada correspondiente a ciudad informal, esto es 1596 barrios, que no cumplen con los procesos de urbanización, han contribuido al deterioro

11 Ministerio de Ambiente Vivienda y Desarrollo Territorial. Subsidios asignados por Fonvivienda entre 2006-2009. ambiental y con asentamientos urbanos en zonas que se definen como de alto riesgo. La mayoría de los 2500000 habitantes ubicados en esta franja son de estrato socio económico 1 y 2 (Secretaría de Planeación Distrital, 1998).

\section{Expansión demográfica urbana en Bogotá}

Bogotá es la ciudad del país que más crecimiento poblacional registra entre 1995 y el 2015 de acuerdo con proyecciones demográficas (Molina, Rueda, Sarmiento y Pardo, 2003), alrededor de 3279427 habitantes, una migración neta promedio de 232300 personas en quinquenios (tabla 2), es decir, aproximadamente 64528 hogares nuevos, teniendo en cuenta que un hogar en Bogotá lo conforman en promedio 3,6 personas.

Tabla 2

Proyección de la población en Bogotá por quinquenio

\begin{tabular}{ccccc}
\hline Año & Total & Cabecera & Resto & $\begin{array}{c}\text { Migrantes } \\
\text { netos }\end{array}$ \\
\hline 1995 & 5724156 & 5708987 & 15169 & 286000 \\
2000 & 6539525 & 6523961 & 15564 & 285000 \\
2005 & 7395610 & 7379710 & 15900 & 245500 \\
2010 & 8235624 & 8219729 & 15895 & 178000 \\
2015 & 9003583 & 8987917 & 15666 & 167000 \\
\hline
\end{tabular}

Nota. Tomado de Dinámica demográfica y estructura funcional de la región Bogotá-Cundinamarca 1973-2020, por H. Molina, J. Rueda, A. Sarmiento y M. Pardo, 2003.

El proceso migratorio hacia Bogotá ha presentado diferentes dinámicas que coinciden con su proceso de desarrollo económico. Las tasas oscilan entre el 11,51 por mil entre $1985-1990$ a 2,08 por mil en el periodo 2010-2015 (tabla 3).

\section{Crecimiento urbano en Bogotá por superficie}

La dinámica del crecimiento urbano en Bogotá se asocia con el gran proceso migratorio hacia la capital no solo desde municipios de Cundinamarca sino de todo el país, que en los últimos tiempos se ha asociado en gran medida con procesos de desplazamiento forzado y con la búsqueda de oportunidades laborales. Generalmente, las soluciones laborales se relacionan 
Tabla 3

Tasas de migración en Bogotá proyecciones 1985-2020

\begin{tabular}{cccccccc}
\hline \multicolumn{10}{c}{ Tasa de migración neta (por mil) } \\
\hline $1985-1990$ & $\mathbf{1 9 9 0 - 1 9 9 5}$ & $\mathbf{1 9 9 5 - 2 0 0 0}$ & $\mathbf{2 0 0 0 - 2 0 0 5}$ & $\mathbf{2 0 0 5 - 2 0 1 0}$ & $\mathbf{2 0 1 0 - 2 0 1 5}$ & $\mathbf{2 0 1 5 - 2 0 2 0}$ \\
\hline 11,51 & 9,77 & 3,90 & 2,47 & 2,23 & 2,08 & 2,00 \\
\hline
\end{tabular}

Nota. Tomado de DANE, censos de población, proyecciones 1973, 1993, 2005.

con el subempleo o con actividades de baja remuneración. La mayoría de los hogares demandantes de vivienda no tienen acceso a los créditos, por lo tanto se generan desarrollos urbanísticos precarios, sin articulación con la ciudad, que derivan en barrios informales en las zonas periféricas.

En la figura 2 se compara el crecimiento urbano formal e informal en Bogotá entre 1950 y el 2000; allí se observa que las hectáreas dedicadas a construcción informal han venido en crecimiento: en la década de los cincuenta fue de 960 hectáreas, mientras que en la década del noventa fue de 2119 hectáreas.

\section{- Crecimiento formal oCrecimiento informal}

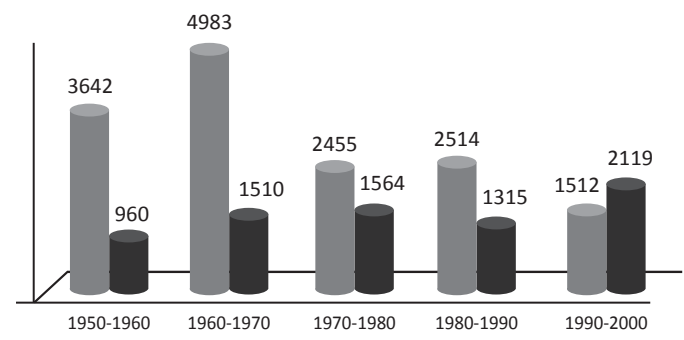

Figura 2. Crecimiento urbano formal e informal en hectáreas, en Bogotá, entre 1950 y el 2000 Tomado de Suelo urbano y vivienda para la población de ingresos bajos, Bogotá, Soacha y Mosquera. Cities Alliance Budget Account. Marzo del 2006.

Porcentualmente, en la figura 3 se observa la variación del área formal e informal en Bogotá; el fenómeno del crecimiento informal en la ciudad pasó del $26 \%$ al $140 \%$ entre la década de los cincuenta y la de los noventa.

\section{Crecimiento urbano de Bogotá por manzanas según localidad entre 1997 y el 2004}

En la tabla 4 se observa que la localidad con mayor crecimiento en manzanas entre 1997 y el 2004 fue Usme, con el 29,39\%; Ciudad Bolívar, el 20,97\%;
Variación porcentual área informal/área formal en Bogotá entre 1950-2000

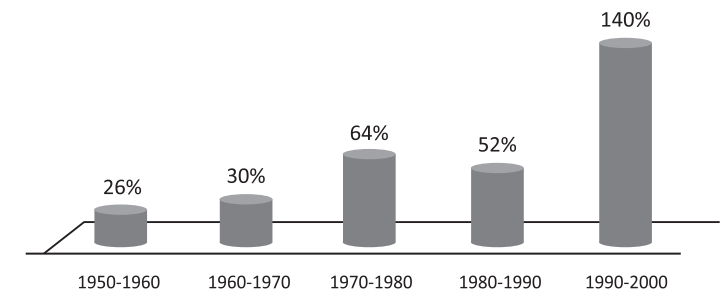

Figura 3. Bogotá Distrito Capital, área informal y formal 19502000. Tomado de Suelo Urbano y Vivienda para la Población de Ingresos Bajos, Bogotá, Soacha y Mosquera. Cities Alliance Budget Account.

Suba, el 19,04\%, y Bosa, con el 13,03\%, en orden de importancia.

\section{Crecimiento de Bogotá por manzanas según estrato socioeconómico}

De acuerdo con la tabla 4, la mayor cantidad de manzanas edificadas por estrato socioeconómico en todas las localidades se ubican en los estratos 1 y 2 , y representan el 63,91\% incluyendo la categoría sin clasificación. El estrato 3 representa el 26,62\% y los estratos altos 4,5 y 6 solamente el 9,47\% del total.

\section{Hogares en déficit de vivienda por localidad en Bogotá 2005}

De acuerdo con los datos del censo del 2005 del DANE, el déficit relativo por localidades en Bogotá tiene en orden de importancia las localidades de Sumapaz, con un déficit del 91\%, Ciudad Bolívar con 53\%, Usme con $47 \%$, Bosa $43 \%$ y Tunjuelito con $40 \%$ que corresponden a localidades con la mayor informalidad en las áreas construidas, como se puede apreciar en la tabla 5 . 
Tabla 4

Manzanas por localidad y estrato en Bogotá 2004

\begin{tabular}{|c|c|c|c|c|c|c|c|}
\hline Localidad & Sin & 1 & 2 & 3 & 4 & 5 & 6 \\
\hline Usaquén & 372 & 183 & 355 & 549 & 317 & 315 & 414 \\
\hline Chapinero & 152 & 118 & 155 & 55 & 197 & 124 & 327 \\
\hline Santa Fe & 124 & 64 & 488 & 143 & 32 & 0 & 0 \\
\hline San Cristobal & 429 & 290 & 2053 & 285 & 0 & 0 & 0 \\
\hline Usme & 580 & 1919 & 1071 & 0 & 0 & 0 & 0 \\
\hline Tunjuelito & 76 & 2 & 529 & 234 & 0 & 0 & 0 \\
\hline Bosa & 400 & 358 & 2447 & 75 & 0 & 0 & 0 \\
\hline Kennedy & 547 & 91 & 2338 & 1884 & 26 & 0 & 0 \\
\hline Fontibón & 396 & 0 & 262 & 731 & 258 & 0 & 0 \\
\hline Engativa & 577 & 38 & 906 & 2446 & 122 & 0 & 0 \\
\hline Suba & 926 & 25 & 2156 & 1085 & 389 & 533 & 145 \\
\hline Barrios Unidos & 111 & 0 & 0 & 797 & 263 & 26 & 0 \\
\hline Teusaquillo & 157 & 0 & 48 & 558 & 3 & 0 & 0 \\
\hline Los Mártires & 96 & 0 & 48 & 558 & 3 & 9 & 0 \\
\hline Antonio Nariño & 76 & 0 & 26 & 489 & 0 & 0 & 0 \\
\hline Puente Aranda & 401 & 0 & 8 & 1423 & 0 & 0 & 0 \\
\hline La Candelaria & 55 & 0 & 74 & 40 & 0 & 0 & 0 \\
\hline Rafael Uribe Uribe & 274 & 289 & 1131 & 838 & 0 & 0 & 0 \\
\hline Ciudad Bolívar & 720 & 3416 & 1151 & 89 & 0 & 0 & 0 \\
\hline \multirow[t]{2}{*}{ TOTAL } & 6469 & 6793 & 15246 & 12279 & 1610 & 1007 & 886 \\
\hline & $14,53 \%$ & $15,25 \%$ & $34,13 \%$ & $26,62 \%$ & $5,16 \%$ & $2,35 \%$ & $1,96 \%$ \\
\hline
\end{tabular}

Nota. DAPD. Gerencia de estratificación y monitoreo del Distrito Capital 2004

El déficit de vivienda se puede estudiar como déficit cuantitativo, que corresponde a la carencia absoluta de vivienda del hogar, y en déficit cualitativo, que corresponde a las soluciones de vivienda que carecen de servicios básicos. En la tabla 5 se observa que el déficit cuantitativo supera al cualitativo, sin embargo el déficit cualitativo requiere inversión social del Gobierno Distrital o Nacional para adecuar las viviendas con el fin de que no estén en precariedad. En la figura 4 se muestra el déficit cualitativo, en el cual se incluyen viviendas que corresponden a ciudad consolidada, es decir a zonas que eran informales y que posteriormente fueron legalizadas, pero que requieren de cobertura en servicios públicos.

\section{Población y desempleo en Bogotá entre el 2001 y el 2011}

Las estadísticas del DANE indican en la tabla 6 que la tasa de desempleo abierto (т. D.) en Bogotá se ha

\section{O Déficit cuantitativo O Déficit cualitativo}

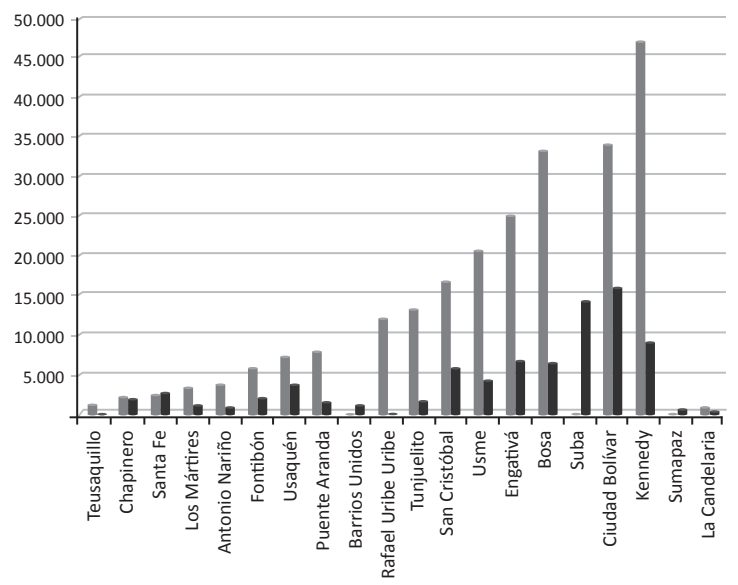

Figura 4. Hogares en déficit de vivienda en Bogotá 2005. Elaboración propia. 
Tabla 5

Déficit de vivienda y clase de déficit en Bogotá por localidades según censo 2005

\begin{tabular}{|c|c|c|c|c|c|}
\hline \multirow[t]{2}{*}{ Localidad } & $\begin{array}{l}\text { Hogares } \\
\text { Sin déficit }\end{array}$ & $\begin{array}{l}\text { Hogares } \\
\text { En déficit }\end{array}$ & $\begin{array}{c}\text { Déficit } \\
\text { Cuantitativo }\end{array}$ & $\begin{array}{c}\text { Déficit } \\
\text { Cualitativo }\end{array}$ & $\begin{array}{l}\text { Déficit / } \\
\text { Sin déficit }\end{array}$ \\
\hline & Total & Total & Total & Total & Variación \\
\hline Usaquén & 121779 & 11270 & 7387 & 3883 & $9 \%$ \\
\hline Chapinero & 43992 & 4323 & 2364 & 1959 & $10 \%$ \\
\hline Santa Fe & 27748 & 5510 & 2614 & 2896 & $20 \%$ \\
\hline San Cristóbal & 87973 & 22622 & 16777 & 5844 & $26 \%$ \\
\hline Usme & 53280 & 24823 & 20579 & 4244 & $47 \%$ \\
\hline Tunjuelito & 37508 & 14962 & 13273 & 1688 & $40 \%$ \\
\hline Bosa & 93119 & 39798 & 33242 & 6556 & $43 \%$ \\
\hline Kennedy & 201438 & 55946 & 46955 & 8991 & $28 \%$ \\
\hline Fontibón & 82127 & 7978 & 5947 & 2031 & $10 \%$ \\
\hline Engativá & 195210 & 31701 & 25093 & 6609 & $16 \%$ \\
\hline Suba & 218996 & 47619 & 33410 & 14209 & $22 \%$ \\
\hline Barrios Unidos & 48737 & 12521 & 11350 & 1172 & $26 \%$ \\
\hline Teusaquillo & 47436 & 2421 & 1301 & 1120 & $5 \%$ \\
\hline Los Mártires & 23627 & 4829 & 3552 & 1276 & $20 \%$ \\
\hline Antonio Nariño & 25476 & 4742 & 3845 & 898 & $19 \%$ \\
\hline Puente Aranda & 63891 & 9504 & 7921 & 1583 & $15 \%$ \\
\hline Candelaria & 6816 & 1383 & 902 & 481 & $20 \%$ \\
\hline Rafael Uribe Uribe & 86787 & 17399 & 12079 & 5320 & $20 \%$ \\
\hline Ciudad Bolívar & 94805 & 49836 & 34008 & 15828 & $53 \%$ \\
\hline Sumapaz & 753 & 687 & 78 & 609 & $91 \%$ \\
\hline TOTAL & 1561498 & 369874 & 282678 & 87197 & \\
\hline
\end{tabular}

Nota. Tomado de DANE. Censo 2005.

reducido en $8,6 \%$ entre el 2001 y el 2011, al pasar del $17,6 \%$ en 2001 al $9 \%$ en el 2011. La tasa de subempleo, por el contrario, se ha incrementado en $5 \%$ entre el 2001 y el 2011. En estos 10 años el subempleo se ubicó en el 34,1\%. Entre el desempleo abierto y el subempleo para el 2011 representan el 41,3\% de la población económicamente activa de Bogotá. Este hecho tiene repercusión en la posibilidad de acceder al crédito de muchas personas, así como de cumplir el cierre financiero, condición necesaria para obtener un subsidio de vivienda, al limitar la capacidad de ahorro de las personas.

\section{El Subsidio Familiar de Vivienda estatal por Fonvivienda}

El subsidio de vivienda como un beneficio que otorga el Estado a los hogares que tienen ingresos inferiores a cuatro salarios mínimos mensuales legales vigentes son asignados por medio del Fondo Nacional de Vivienda (Fonvivienda), a hogares informales que no están vinculados a ninguna Caja de Compensación previo cumplimiento de unos requisitos de ley, que permiten que el subsidio cumpla con su finalidad, es decir, la adquisición de una "vivienda digna". Como se ve en la figura 8 pueden ser asignados por las cajas de compensación familiar a empleados afiliados. En la figura 6, se compara los subsidios estatales pagados con los asignados para establecer un índice de eficiencia. Los índices más bajos están entre los años 2008-2010 al ubicarse por debajo del 65\% del cumplimiento.

En el 2008, se asignaron 1340 subsidios y fueron pagados 718; en el 2009, se asignaron 1880 y se pagaron 1218; en el 2010, se asignaron 2473 créditos y se pagaron únicamente 991. Estas diferencias entre 
Tabla 6

Población y desempleo entre 2001-2011, Bogotá y total nacional

\begin{tabular}{cccccc}
\hline & Nacional & Bogotá & Nacional & Bogotá & Bogotá \\
\cline { 2 - 6 } AÑS & T. D. Abierto & T. D. Abierto & Población total & Población total & $\begin{array}{c}\text { Tasa de subempleo } \\
\text { subjetivo }\end{array}$ \\
\hline 2001 & 13,8 & 17,6 & 39280 & 6397 & 29,1 \\
2002 & 14,2 & 16,6 & 40179 & 6505 & 34,9 \\
2003 & 13 & 15,6 & 40681 & 6612 & 33,3 \\
2004 & 12,3 & 13,5 & 41183 & 6718 & 31,8 \\
2005 & 10,9 & 12,1 & 41687 & 6824 & 34 \\
2006 & 10,5 & 10,6 & 42186 & 6930 & 31,5 \\
2007 & 10,1 & 9,7 & 42690 & 7034 & 30,6 \\
2008 & 10,4 & 9,6 & 43196 & 7249 & 29,2 \\
2009 & 11,1 & 11 & 43706 & 7348 & 24,2 \\
2010 & 10,8 & 10,1 & 44218 & 4452 & 32,2 \\
2011 & 10 & 9 & 435 & 34,1 \\
\hline
\end{tabular}

Nota. Tomado de DAne Mercado laboral, encuesta de hogares. Proyección entre 2001-2011.

subsidios asignados y pagados, obedecen a que muchos hogares no tienen capacidad de ahorro para cumplir con el cierre financiero exigido al beneficiario (figura 6).

Los subsidios estatales se asignan y entregan por medio de 11 bolsas que tienen diferentes condiciones y requisitos para su acceso. La Bolsa Ordinaria es un mecanismo por medio del cual el Estado entrega el subsidio a aquellos hogares constituidos por trabajadores independientes, que cumplen con los requisitos que la ley exige. Por Bolsa Ordinaria se asignaron en Bogotá 7793 subsidios y fueron pagados 4920: una

Indicador de eficiencia del subsidio estatal en Bogotá entre 2003-2011. Pagados/asignados

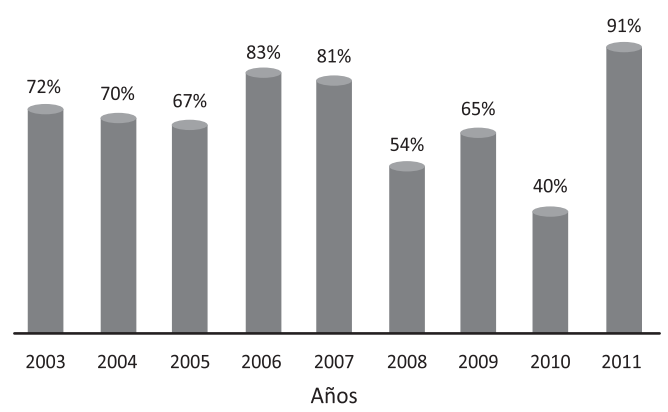

Figura 5. Eficiencia del subsidio Estatal en Bogotá 2003-2011. Elaboración propia. eficiencia del 63\% (véase tabla 7 y figura 7). Como se observa en la tabla 10, la Bolsa para Desplazados es la más representativa en la asignación de subsidios; en el periodo 2003-2011, se asignaron 7929 subsidios y se pagaron 4644: una eficiencia del 58\% (figura 7). Esta Bolsa para Desplazados es tal vez a la que se le da prioridad en la asignación, por corresponder a población vulnerable víctima del conflicto armado y objeto de la atención del Estado en su política social; sin embargo, la eficiencia es baja (58\%), a pesar de que no se exige la condición de ahorro previo.

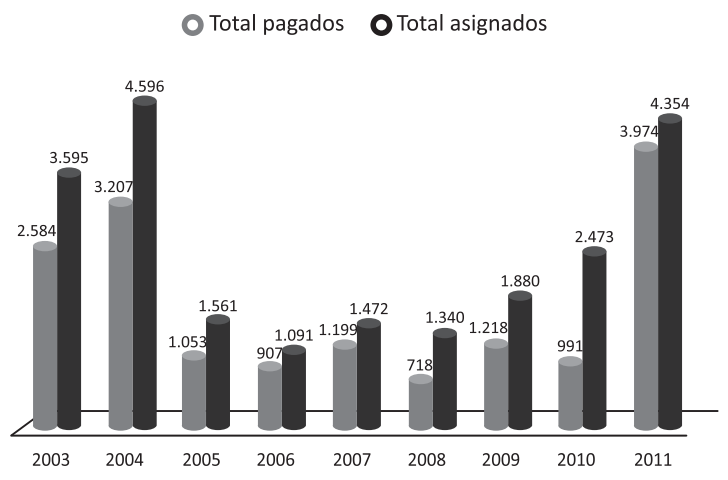

Figura 6. Subsidios asignados y pagados en Bogotá 2003-2011. Elaboración propia. 
Tabla 7

Subsidio estatal asignados y pagados en Bogotá 2003-2011, según tipo de bolsa

\begin{tabular}{ccccccccc}
\hline 2003-2011 & Atentados & $\begin{array}{c}\text { Desastres } \\
\text { Naturales }\end{array}$ & Desplazados & Ordinaria & Mejoramiento & $\begin{array}{c}\text { Ahorro } \\
\text { Programado }\end{array}$ & Recicladores \\
\hline PAGADOS & 19 & 508 & 4644 & 4920 & 21 & 5707 & 23 \\
ASIGNADOS & 3985 & 541 & 7929 & 7793 & 30 & 5996 & 24 \\
\hline
\end{tabular}

Nota. Elaboración propia.

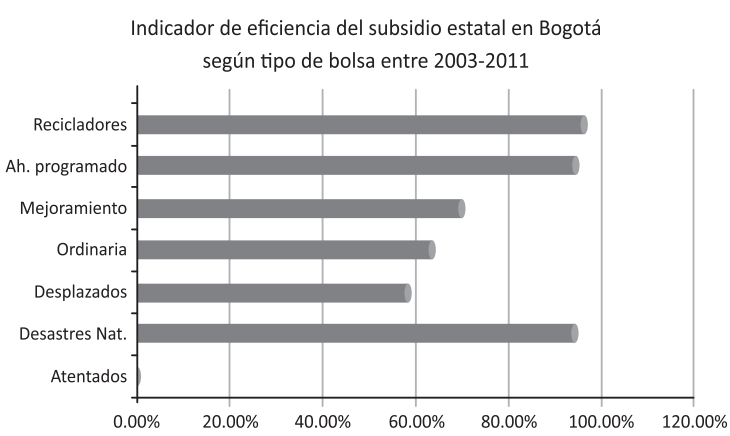

Figura 7. Subsidio Estatal en Bogotá según tipo de bolsa 2003-2011. Elaboración propia.

\section{Subsidio familiar de vivienda: cajas de compensación familiar}

El subsidio se asigna a hogares de trabajadores afiliados a cajas de compensación familiar, considerados empleados formales. El índice de eficiencia del subsidio familiar de vivienda asignado por cajas de compensación familiar está por encima del $60 \%$ promedio en el periodo 2000-2011. En el 2003, este índice de eficiencia superó el $90 \%$ ya que, en ese año, se dio aplicabilidad a las normas vigentes para regular el subsidio de vivienda, como se puede observar en la figura 8. Se da una referencia de la eficiencia del subsidio familiar en las cajas de compensación, entregados o asignados entre 2000 y 2011.

\section{Consideraciones de la oferta de vivienda}

La vivienda tipificada como de interés social (vis) es aquella que no supera los 135 salarios mínimos mensuales legales vigentes (sMmLv) y la de interés Prioritario es aquella que no supera los 70 smmLv: en esta categoría, están los beneficiarios del SFV y la Vivienda que No es de Interés Social (No VIS). La
Eficiencia del subsidio familiar en las cajas de compensación familiar Entregados/asignados total nacional entre 2000-2011

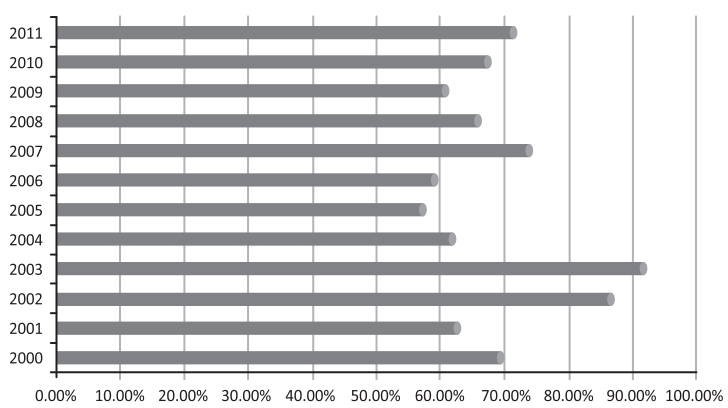

Figura 8. Eficiencia del Subsidio Familiar en Cajas de Compensación Familiar. Elaboración propia.

política de vivienda se orienta más a favorecer a los hogares de menor ingreso para que adquieran una "vivienda digna".

\section{Área construida}

Según estadística de la Cámara Colombiana de la Construcción (Camacol), el área en metros cuadrados construida para vis, entre 1998 y el 2012, está por debajo del 1500000 de metros cuadrados (figura 9); mientras que la vivienda No vis duplica la cantidad de metros cuadrados construidos en la vis. Las entidades financieras respaldan proyectos más costosos dirigidos a hogares con capacidad de ahorro, que estén en capacidad de pagar la tasa de interés de financiación del proyecto habitacional.

\section{Obras culminadas y obras en proceso}

Como se observa en la tabla 11, las obras culminadas para VIs en Bogotá se incrementaron en 5667 obras correspondientes al 47,26\% entre el 2001 y el 2012, mientras que las obras en proceso se incrementaron en el mismo periodo en un 96,75\%. Esta dinámica contrasta con la vivienda No vis, que en el mismo 


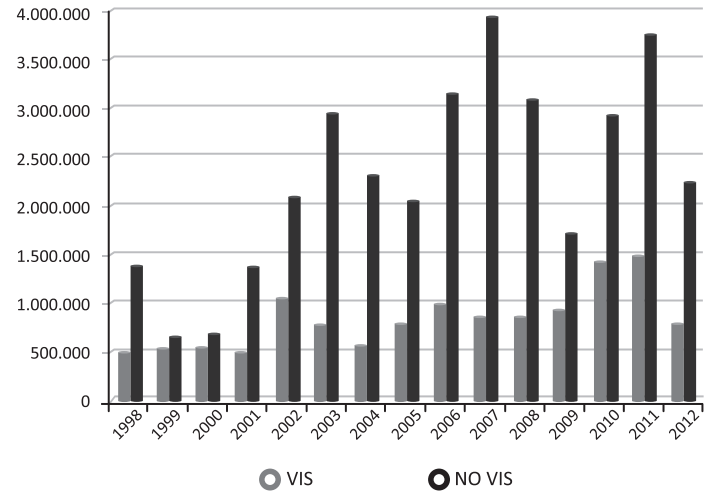

Figura 9. Área construida en $\mathrm{m}^{2}$ para Bogotá según tipo de vivienda 1998-2012. Elaboración propia.

Tabla 8

Vivienda de interés social en Bogotá 2001-2012

\begin{tabular}{lcc}
\hline AÑOS & $\begin{array}{c}\text { OBRAS } \\
\text { CULMINADAS }\end{array}$ & $\begin{array}{c}\text { OBRAS } \\
\text { EN PROCESO }\end{array}$ \\
\hline 2001 & 11992 & 32638 \\
2002 & 25864 & 68880 \\
2003 & 22623 & 42770 \\
2004 & 16416 & 38607 \\
2005 & 16122 & 39061 \\
2006 & 19194 & 57088 \\
2007 & 18467 & 75077 \\
2008 & 23119 & 71539 \\
2009 & 18074 & 58872 \\
2010 & 21330 & 66893 \\
2011 & 23478 & 82446 \\
2012 & 17659 & 64214 \\
\hline
\end{tabular}

Nota. Tomado de Colombia construcción en cifras, por Cámara Colombiana de la Construcción [Camacol], 2015.

periodo 2001-2012, para las obras culminadas se incrementó en más del $400 \%$ y para las obras en proceso, en más del 700\% (tabla 9).

\section{VIS en unidades para Bogotá}

Como se muestra en la figura 11, las vis culminadas en el periodo 2001-2012 se ubicaron en 19445 unidades promedio en el periodo 2001-2012. Iniciaron en el periodo analizado con 11992 unidades culminadas, las obras en proceso superan en tres veces a las obras culminadas. Este hecho se justifica por la
Tabla 9

No vivienda de interés social en Bogotá 2001-2012

\begin{tabular}{ccc}
\hline AÑOS & $\begin{array}{c}\text { OBRAS } \\
\text { CULMINADAS }\end{array}$ & $\begin{array}{c}\text { OBRAS } \\
\text { EN PROCESO }\end{array}$ \\
\hline 2001 & 3346 & 12596 \\
2002 & 7116 & 30501 \\
2003 & 11580 & 39675 \\
2004 & 16017 & 63241 \\
2005 & 17012 & 79278 \\
2006 & 18429 & 67948 \\
2007 & 18128 & 122333 \\
2008 & 24015 & 140217 \\
2009 & 24245 & 114963 \\
2010 & 19753 & 117408 \\
2011 & 21963 & 128246 \\
2012 & 18824 & 107441 \\
\hline
\end{tabular}

Nota. Tomado de Colombia construcción en cifras, por Camacol, 2015.

cantidad de trámites ante entidades de servicios públicos para la aprobación de cobertura y demás tramites de licencias ante las entidades competentes que tardan aproximadamente cinco meses en definir la aprobación del caso. En las unidades de vivienda NO vis, la tendencia en las obras culminadas es más acelerada, ya que, en el 2001, las soluciones de vivienda fueron de 3346 y en el 2012 de 18824 unidades. Las obras en proceso NO vis superaron a las vis en el 2012 , en el $67,32 \%$.

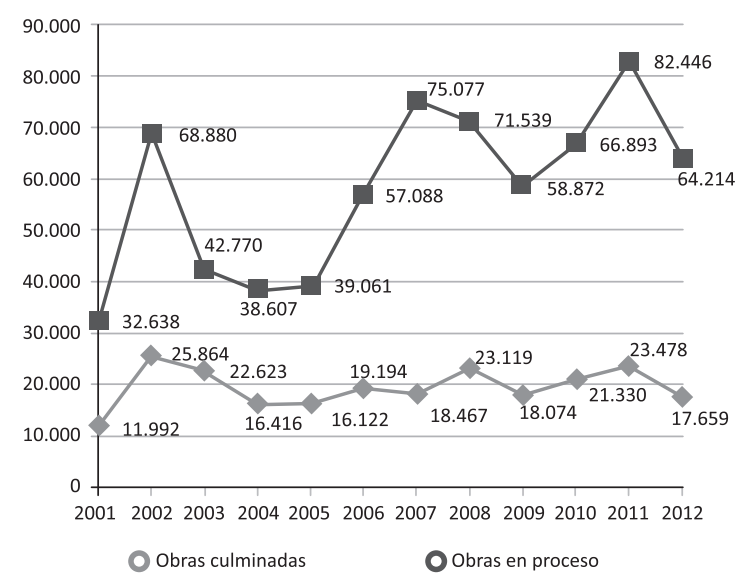

Figura 10. Vivienda de interés social en unidades para Bogotá 2001-2012. Elaboración propia http://camacol.co/informacioneconomica/cifras-sectoriales/construccion-en-cifras 


\section{Conclusiones}

La política de vivienda empieza a consolidarse en Colombia a partir de la década de los ochenta, para mitigar el impacto social que causaba la migración hacia las grandes ciudades, no dirigida sino forzada por situaciones del conflicto armado en el área rural y por ausencia del Estado en esas zonas deprimidas con políticas que trataran de solucionar la ausencia de oportunidades laborales y la carencia de saneamiento básico. La política se reorienta de lo económico a lo social, ya que las políticas que estimulan el crecimiento económico se deben traducir en un mejor impacto social, reducción del desempleo, mayores niveles de ingreso y mejor calidad de vida. Este hecho ha sido replicado por entidades multilaterales como la Organización de las Naciones Unidas (ONU) y la Comisión Económica para América Latina y el Caribe (Cepal), con diferentes estudios que abordan los temas de la pobreza y la calidad de vida en Latinoamérica. Sus recomendaciones sobre calidad de vida y "vivienda digna", que es aquella con calidades de construcción, un espacio apropiado, dotación de servicios públicos, sin degradar el paisaje urbanístico ni el patrimonio histórico de las ciudades, fueron incorporadas por las políticas internas de los países en vías de desarrollo. En general, todas las políticas de vivienda fueron diseñadas básicamente para soluciones habitacionales nuevas, creando una expansión horizontal de las ciudades. Sin embargo, el déficit de vivienda en las ciudades mantiene aún su tendencia creciente porque la dinámica poblacional en los centros urbanos ha generado una informalización del suelo y la construcción con altos costos de legalización y de suministro de servicios públicos domiciliarios.

En Bogotá, entre 1998 y el 2001, la ciudad informal era del $23 \%$, la ciudad consolidada del $65 \%$ y la ciudad nueva representaba solamente el $12 \%$, es decir, hay una prevalencia del carácter informal de la vivienda. En términos de barrios de estrato socioeconómico 1 y 2 , la ciudad informal en el periodo analizado estaba conformada por 1596 barrios que no cumplen con los procesos de urbanización, alrededor de 2500000 habitantes en zonas de alto riesgo. Bogotá es la ciudad del país que mayor crecimiento poblacional registra entre 1995 y 2015; de acuerdo con proyecciones demográficas (Molina, Rueda, Sarmiento y Pardo, 2003), alrededor de 3279427 habitantes, una migración neta promedio de 232300 personas en quinquenios, aproximadamente 64528 hogares nuevos, teniendo en cuenta que un hogar en Bogotá lo conforman en promedio 3,6 personas. Esa migración neta promedio es la que está alimentando las cifras del déficit de vivienda en la ciudad capital. De acuerdo con la información suministrada por el DANE en el censo del 2005, el déficit relativo por localidades estaba concentrado así: Sumapaz con un déficit del $91 \%$, Ciudad Bolívar con $53 \%$, Usme con $47 \%$, Bosa con $43 \%$ y Tunjuelito con $40 \%$, que corresponden a las localidades con la mayor informalidad en las áreas construidas.

Las políticas en materia de vivienda se articulan con base en el déficit cuantitativo de vivienda, es decir, la cantidad de viviendas que requieren los hogares que no poseen techo propio ya que el déficit cualitativo se relaciona con viviendas que requieren mejoramiento, servicios públicos, entre otros, con una inversión social alta. En Colombia, la política de vivienda inicialmente asignaba la responsabilidad de la oferta al Estado con el Instituto de Crédito Territorial, después con el Inurbe, finalmente, la ejecución de esa política la comparten con los particulares, y con entidades del sector financiero que financian la compra de la vivienda. El Estado otorga un SFV a las familias de escasos recursos económicos, para dinamizar la demanda, aplicable al tipo de vis (Ley 3 de 1991), aquella cuyo precio no supera los 135 salarios mínimos mensuales legales vigentes y con un área construida promedio de 54 metros cuadrados.

La demanda de vivienda se puede clasificar en demanda de vis, cuyo precio no supera los 165 SMMLV, es decir, alrededor de 65 millones de pesos, un área construida no mayor a 54 metros cuadrados, y el solicitante recibe subsidios siempre y cuando no tenga otra propiedad y sus ingresos no superen los 4 SMMLV y, por otra parte, vivienda que no se considera como de interés social (NO VIS), corresponde a soluciones de vivienda de alto costo, viviendas que no reciben subsidio por tener área construida superior a los 54 metros cuadrados y precios altos.

En la teoría económica, la demanda de un bien está relacionada con el precio y con el ingreso, entre otras variables, que para la pertinencia econométrica corresponde a ecuaciones de identidad; sin embargo, hay estudios que se limitan a indagar sobre la demanda desde la dinámica del crédito hipotecario, los ingresos y el producto interno bruto (PIB).

La conclusión con base en la poca sensibilidad que se registra en los resultados del modelo econo- 
métrico es que hay poca efectividad del subsidio de vivienda en el dinamismo de la demanda de la vis. El Estado a nivel global y la administración distrital a nivel particular no están en la capacidad presupuestaria para solucionar el déficit de vivienda en Bogotá ni en el país porque no hay recursos suficientes y tampoco hay focalización de las familias en déficit habitacional. La demanda de vis, de acuerdo con los resultados del modelo, tiene mayor sensibilidad a la variación en el desempleo, por lo tanto, el déficit de vivienda es más estructural. Si se les otorgan subsidios de vivienda a las familias para la cuota inicial, el pago del saldo del precio necesita una estabilidad en el ingreso que sería resultado de una menor tasa de desempleo abierto. La poca efectividad del subsidio se justifica también en la informalidad de la construcción, que tiene altos costos en su consolidación, servicios públicos, vías de acceso, transporte, etcétera, que exige importantes recursos para la legalización de la vivienda informal. La demanda de vis es sensible a la variación en el precio, de acuerdo con el resultado del modelo, lo que a su vez refleja que el subsidio no está determinado por la demanda de vivienda.

Finalmente, la "construcción social del espacio" representa grandes desafíos para las cooperativas de vivienda que aplican una serie de tecnologías sociales, partiendo desde el autofinanciamiento, la utilización de mano de obra propia para reemplazar procesos maquinados, la utilización de materiales alternativos propios de la región para ahorro energético y transporte, así como la reducción de los costos futuros de sostenimiento mediante diseños alternativos para el manejo de aguas servidas, desechos y residuos sólidos adicionales a la explotación sostenible de recursos locales, para implementar proyectos productivos generadores de empleo.

\section{Referencias}

Cámara Colombiana de la Construcción. [Camacol]. (2015). Colombia construcción en cifras. Bogotá: Camacol. Disponible en http://camacol.co/informacion-econo$\mathrm{mica} /$ cifras-sectoriales/construccion-en-cifras

Currie, L. (1993). La teoría en que se basa la estrategia del sector líder. Cuadernos de Economía. 13(18-19), $225-$ 230 .

Declaración de Vancouver sobre asentamientos humanos. (Compromisos de los gobiernos en adelantar acciones dirigidas a resolver los principales problemas de los asentamientos humanos. Vancouver; Canadá: United Nations Conference on Human. Del 31 de mayo al 11 de junio de 1976).

Dirección Nacional de Planeación. [DNP]. (1972). Suelo urbano y vivienda para la población de ingresos bajos, Bogotá, Soacha y Mosquera. Bogotá: Cities Alliance Budget Account.

Le Blanc, D. (2005). A Methodology with Application to Morocco. Economic Evaluation of Housing Subsidy Systems. Urban Unit World Bank.

Ley 3. Por la cual se crea el Sistema Nacional de Vivienda de Interés Social, se establece el subsidio familiar de vivienda, se reforma el Instituto de Crédito Territorial, ICT, y se dictan otras disposiciones. Publicada en el Diario Oficial No. 39631 del 15 de enero de 1991. Colombia.

Ministerio de Ambiente, Vivienda y Desarrollo Territorial. (2004). Decreto 975 del 2004. Por el cual se reglamentan parcialmente las Leyes 49 de 1990, 3 de 1991, 388 de 1997, 546 de 1999, 789 de 2002 y 812 de 2003 en relación con el Subsidio Familiar de Vivienda de Interés Social en dinero para áreas urbanas. Diario Oficial N. 45509 de abril 2 de 2004. Colombia.

Ministerio de Desarrollo Económico. (2000). Decreto 2620 del 2000. Por el cual se reglamentan parcialmente la Ley $3^{a}$ de 1991 en relación con el Subsidio Familiar de Vivienda en dinero y en especie para áreas urbanas, la Ley 49 de 1990,en cuanto a su asignación por parte de las Cajas de Compensación Familiar y la Ley 546 de 1999, en relación con la vivienda de interés social. Diario Oficial N. ${ }^{\circ} 44267$ de diciembre 22 de 2002.

Molina, H., Rueda, J., Sarmiento, A. y Pardo, M. (2003). Dinámica demográfica y estructura funcional de la región Bogotá-Cundinamarca 1973-2020. Bogotá: Secretaría Distrital de Planeación.

Mokate, K. M. (2001). Eficacia, eficiencia, equidad y sostenibilidad: ¿Qué queremos decir? (Documentos de trabajo del INDES). Washington.

Pacto Internacional de Derechos Económicos, Sociales y Culturales [ICESCR]. XXI Asamblea General de las Nacionaes Unidas. Naciones Unidas. (16 de diciembre de 1966).

Suárez, H. D. (2003). Evaluación de la política pública en procesos de restablecimiento de la población desplazada desde un enfoque de derecho. Bogotá; D. C.: Defensoría del Pueblo. http://www.alcaldiabogota.gov.co/sisjur/ normas/Norma1.jsp?i=4982Alcaldía Mayor de Bogo- 
tá. Planes de Desarrollo. Históricos. http://camacol. Suelo Urbano y Vivienda para la Población de Ingresos Baco/informacion-economica/cifras-sectoriales/consjos, Bogotá, Soacha y Mosquera . (2006). Bogotá: Cities truccion-en-cifras Alliance Budget Account. 